\title{
DATA AND TECHNIQUES FOR STUDYING THE URBAN HEAT ISLAND EFFECT IN JOHANNESBURG
}

\author{
C. H. Hardy*, A. L. Nel \\ Department of Mechanical Engineering Science, University of Johannesburg, Johannesburg, South Africa - \\ caroline.h.hardy@gmail.com, andren@uj.ac.za
}

KEY WORDS: Urban Heat Island, Remote Sensing, Thermal Infrared, Land Surface Temperature, Multi-temporal

\begin{abstract}
:
The city of Johannesburg contains over 10 million trees and is often referred to as an urban forest. The intra-urban spatial variability of the levels of vegetation across Johannesburg's residential regions has an influence on the urban heat island effect within the city. Residential areas with high levels of vegetation benefit from cooling due to evapo-transpirative processes and thus exhibit weaker heat island effects; while their impoverished counterparts are not so fortunate. The urban heat island effect describes a phenomenon where some urban areas exhibit temperatures that are warmer than that of surrounding areas. The factors influencing the urban heat island effect include the high density of people and buildings and low levels of vegetative cover within populated urban areas. This paper describes the remote sensing data sets and the processing techniques employed to study the heat island effect within Johannesburg. In particular we consider the use of multi-sensorial multi-temporal remote sensing data towards a predictive model, based on the analysis of influencing factors.
\end{abstract}

\section{INTRODUCTION}

Johannesburg is South Africa's most populous city and the provincial capital of the Gauteng province. According to (Statistics South Africa, 2012), in 2011 Johannesburg had a population of 4434827 people living in an area of only $1645 \mathrm{~km}^{2}$. Johannesburg's population is growing at a rapid pace, in the decade between Census 2001 and Census 2011 the population increased by more than one million inhabitants. The City of Johannesburg Metropolitan Municipality is both the financial hub and the core of the Gauteng City-Region (GCR) conurbation. The GCR conurbation has developed into a contiguous urban region comprised of five constituent municipalities; the City of Johannesburg Metropolitan, City of Tshwane Metropolitan, Ekurhuleni Metropolitan, West Rand District and Sedibeng District.

Johannesburg and the GCR have been subject to urban growth and environmental change, particularly in the region's informal settlements as people migrate to cities within the GCR. Urbanization has an influence on the natural environment as natural surfaces are replaced by man-made structures and increased anthropogenic activity leads to greater emissions of aerosols and trace gases into the atmosphere. The result is the development of urban heat islands (UHIs) within the city and informal settlements.

In this paper we describe the data and methods used to the study of the urban heat island effect (UHIE) in Johannesburg.

\subsection{Remote Sensing and the urban heat island}

The surface urban heat island (SUHI) refers to urban areas where the surface temperature of the area is higher than that of surrounding non-urban areas (Voogt and Oke, 2003). The SUHI may be present both during the day and at night, and is influenced by factors such as anthropogenic activities, urban function, urban landscape and form, temporal aspects, climate, weather, topography and location (Arnfield, 2003, Taha, 1997).

\footnotetext{
${ }^{*}$ Corresponding author.
}

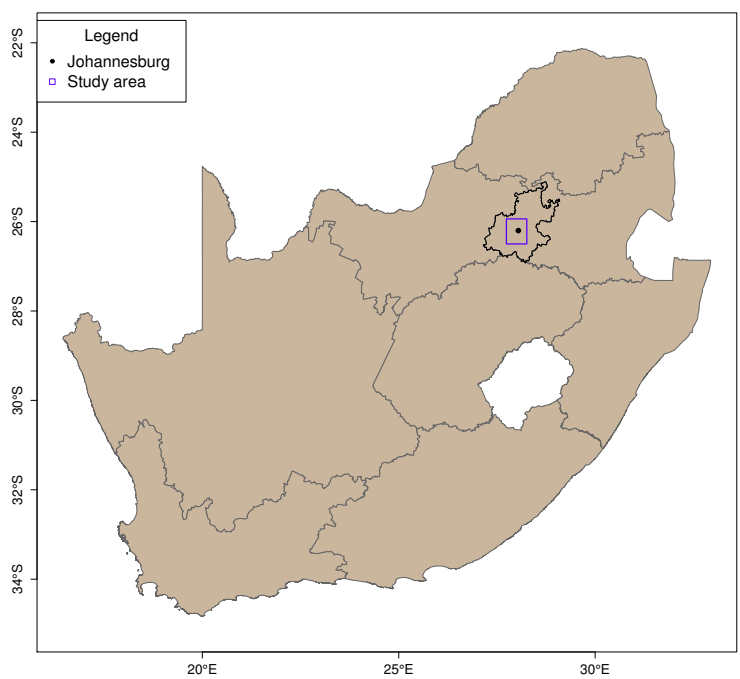

Figure 1: Map of South Africa showing the location of Johannesburg (denoted by a dot) and the study area as indicated by a blue rectangle.

The urban landscape is not a homogeneous surface as it is comprised of different materials and structures; the surface properties, thermal characteristics and placement of these materials and natural features such as rivers and hills describe the urban form. Temporal aspects refer to the time of day and seasonal variation. Urban function is characterized by the primary land use and activities undertaken in the urban area. The urban function of an area affects the amount of energy used and the level of aerosols and gas emissions. Climate and weather influence the SUHI as clouds block solar radiation from reaching the Earth's surface, while winds may cause the heat which is usually trapped in the city to dissipate.

In order to effectively study the SUHI, thermal sensors are required to detect heat radiating from the urban surface. Remotely sensed thermal observations of the Earth's surface can be used to 
study the thermal state of the surface and to analyze the UHI if the observations provide sufficient resolution. The spatial resolution of the data describes the level of spatial detail recorded while the temporal resolution refers to the time between consecutive images. If the temporal resolution of the data is too low, the gaps between image acquisitions may be too large to perform a reliable long-term study. Low spatial resolution data is unable to reflect changes in small objects in the scene. Spatial and temporal resolution are inversely related, thus it is not possible to obtain data with a high temporal resolution while maintaining a high spatial resolution.

\subsection{Research Objective}

This paper describes the preliminary work undertaken towards the development of a predictive UHI model for Johannesburg to determine how the UHIs within Johannesburg evolve over time.

\section{MATERIALS AND METHODS}

\subsection{Study Area}

The primary focus area of this study is the Greater Johannesburg Metropolitan area. The study area, depicted in Figure 2, covers approximately $60 \mathrm{~km}$ by $70 \mathrm{~km}$ which includes the primary focus area and surroundings. The area was selected to study the UHIE, since Johannesburg is South Africa's most populous city.

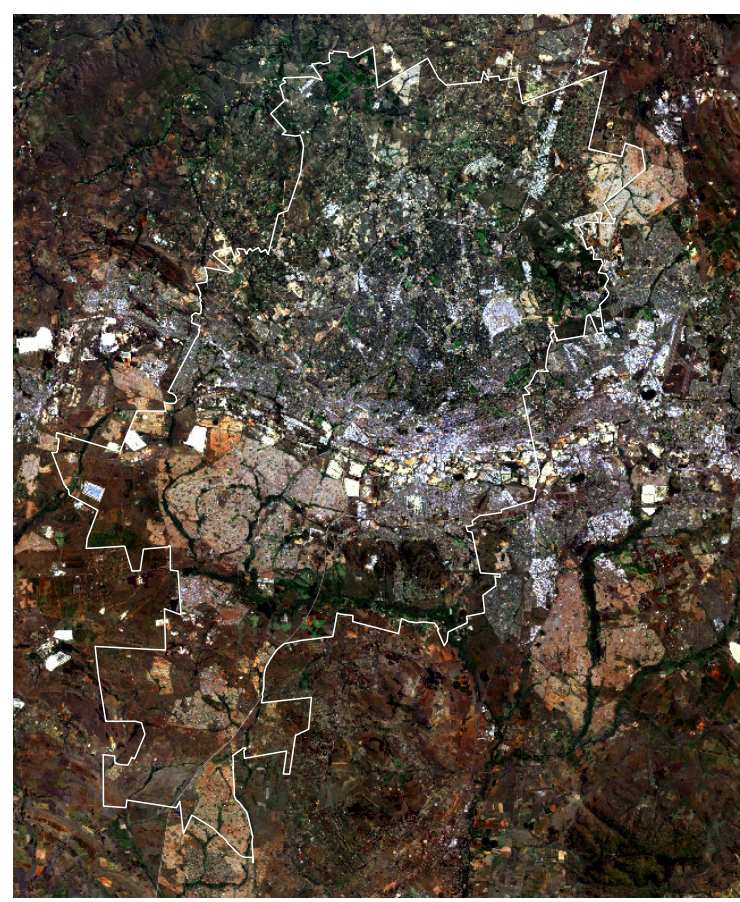

Figure 2: Landsat 7 image (15 March 2003) of the study area. The white boundary line indicates the extent of Greater Johannesburg Metropolitan area. The study area is centred over the Johannesburg CBD.

UHI studies have been conducted in many cities around the world (Peng et al., 2012, Roth and Chow, 2012, Arnfield, 2003) but few studies have been conducted in African cities (Tyson et al., 1972, Goldreich, 1985, Adebayo, 1987). The urban form of Johannesburg differs from many other cities, as Johannesburg is not a compact city and it was not founded near a river or the ocean. Unlike many large cities, Johannesburg does not consist of a dense network of city blocks. Instead Johannesburg is spread out and has many residential suburbs and distributed business centres. Johannesburg also contains over 10 million trees and is therefore referred to as an urban forest. Studies have shown vegetation to have a mitigating effect on the UHI. However not all parts of Johannesburg contain high levels of vegetation. Areas which are most deficient in vegetation are the city's urban centres, such as Sandton and Randburg, and informal settlements.

\subsection{Remotely sensed data}

Cloud-free thermal infrared data is required for UHI studies. High spatial resolution data is preferred over lower resolution data for urban studies. Advanced Spaceborne Thermal Emission and Reflection Radiometer (ASTER) and Landsat offer high resolution thermal infrared data; ASTER thermal infrared bands have a resolution of $90 \mathrm{~m}$, while Landsat 4/5 Thematic Mapper (TM) thermal infrared data have a $120 \mathrm{~m}$ resolution and the Landsat 7 Enhanced Thematic Mapper Plus (ETM+) thermal infrared data has a resolution of 60m. Landsat 8, which was launched in February 2013, acquires thermal infrared data at $100 \mathrm{~m}$ pixel-resolution. All thermal infrared data from Landsat 4/5 TM, Landsat 7 ETM+ and Landsat 8 thermal infrared data are resampled to $30 \mathrm{~m}$.

Landsat 4/5 TM and 7 ETM+ data of Johannesburg is only available for day time scenes, acquired at approximately 10:00AM local time. ASTER data is not appropriate for this study, except for validation purposes, because the available ASTER data is both temporally sparse and does not cover the full study area. Satellites which offer high resolution data typically have a long repeat cycle; ASTER and all Landsat satellites return to the same path once every 16 days. With long revisit times, there is a low chance of acquiring high resolution cloud-free data over areas which are frequently cloudy. Johannesburg's rainy season occurs in summer, thus many Landsat scenes over Johannesburg in summer contain cloud cover. In order to increase the chances of acquiring cloud-free data, low resolution sources must be considered as these satellites typically have short revisit times of between one and three days.

Only historical data is available from the ENVISAT Advanced Along Track Scanning Radiometer (AATSR) program as ENVISAT is no longer operational, while current and historical low resolution thermal infrared data is available from Moderate Resolution Imaging Spectroradiometer (MODIS) and Advanced Very High Resolution Radiometer (AVHRR). Thermal infrared data from MODIS, AVHRR and AATSR all have a nominal pixel resolution of $1 \mathrm{~km}$.

ENVISAT AATSR data, which has a revisit time of 3 days and provides both day and night scenes (acquired at approximately 10:00AM and 10:00PM local time), been used in this study. A disadvantage low spatial resolution data is that not possible to resolve finer scale details, such as vegetation levels and accurate land cover. This problem is overcome by combining AATSR data with classified Landsat data from a date representative of the AATSR scene, in this way annual and seasonal land cover and land use change can be factored into the LST values derived from the AATSR data.

\subsection{Case study}

In this study data from Landsat $5 \mathrm{TM}$, Landsat $7 \mathrm{ETM}+$ and ENVISAT AATSR have been employed to study the UHIE in Johannesburg. The Geospatial Data Abstraction Library (GDAL) and the Basic ERS \& Envisat (A)ATSR and Meris (BEAM) Toolbox 
were used to preprocess and reproject all AATSR Level 2 (ATS NR 2P) and Landsat data. The preprocessing procedure entails; reprojecting to UTM zone 35S using the WGS84 ellipsoid, image coregistration and spatial subsetting to clip the data to the extent of the study area. The extent of the study region is depicted in Figure 2.

After preprocessing, all processing of the AATSR and Landsat data was performed using $\mathrm{R}$ ( $\mathrm{R}$ Core Team, 2015) and the $\mathrm{R}$ landsat package (Goslee, 2011). Using the landsat package, the Landsat thermal bands were converted to temperature maps. The ATS NR 2P data is a AATSR product which contains land surface temperature (LST) and normalized difference vegetation index (NDVI) data. Algorithm details for AATSR operational LST retrieval can be found in (Prata, 2002). An example of the AATSR LST data can be seen in Figure 4.

Unsupervised k-means classification was performed on the Landsat data to classify the data according to seven land cover classes. Example output of the classification process is shown in Figure 3. Landsat 7 ETM+ data which contain gaps due to the Landsat 7 scan line corrector (SLC) error require gap filling prior to classification, gap filling has been covered extensive in the literature (Chen et al., 2011, Weiss et al., 2014, Maxwell et al., 2007).

Thirty four measurements points were selected according to the Landsat land cover classification map and then manually reclassified into six land use classes according to the original land cover class and geographic location; outlying non-urbanized/rural areas, airports/impervious surface, urban centres (i.e. Sandton, Fourways and Randburg), urban green areas, Johannesburg CBD and high density residential settlements. The 34 points were used to to extract LST values from the combined Landsat and AATSR dataset.

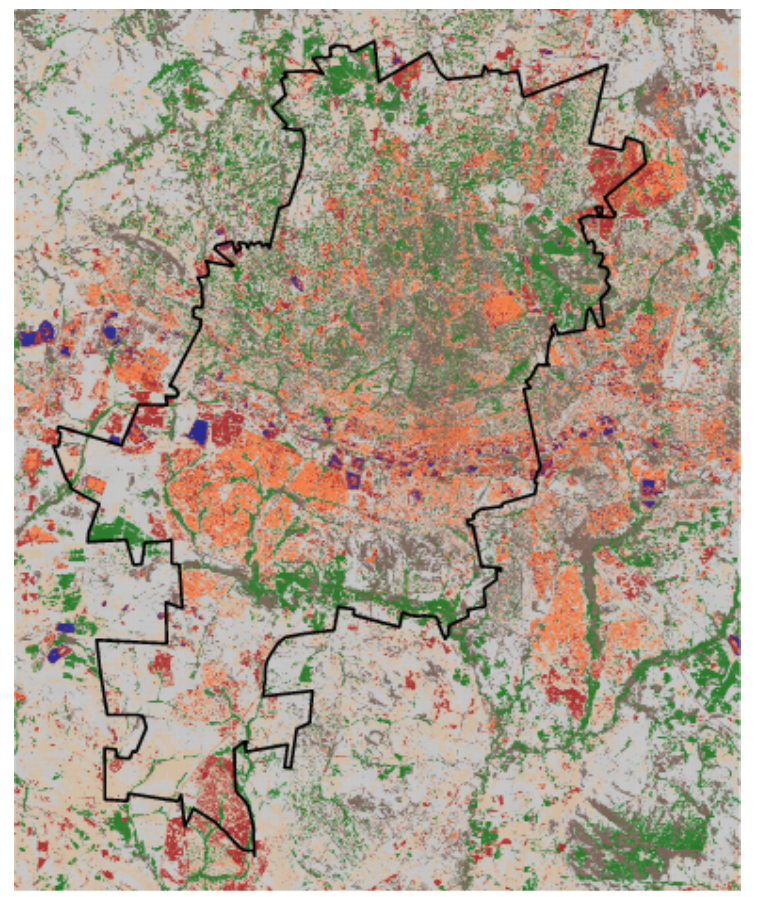

Figure 3: Result of k-means classification on Landsat 7 image (15 March 2003) of the study area.

It is not possible to acquire a full cloud-free dataset; thus to maximize the number of days for which valid data is available and simultaneously minimize cloud contamination of LST values in partially cloudy scenes we extract mean LST values from the data. The mean LST values is extracted from each LST image in the dataset from a predefined neighbourhood around the geographic coordinates of the centre pixel for each of the 34 measurement points.

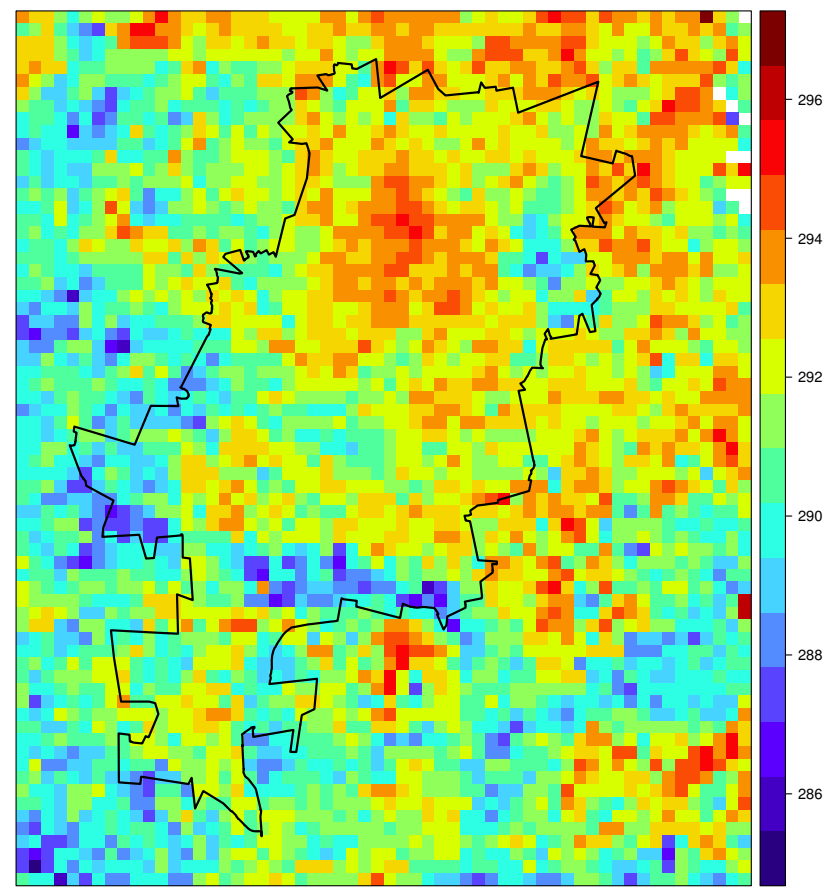

Figure 4: A land surface temperature map from AATSR data shows the night-time Johannesburg urban heat island on 14 March 2003 at 22:25 local time. The data has a nominal pixel size of $1 \mathrm{~km}$ by $1 \mathrm{~km}$.

\section{RESULTS}

The Landsat classification map was used to identify measurements points representative of the seven land cover classes identified. The urban heat island intensity (UHII), which is described by the equation $\Delta T_{u-r}=T_{u}-T_{r}$, was calculated by subtracting the mean temperature of the non-urbanized class from the mean temperature of the each of the other land use classes for each day represented in the satellite data dataset. For the period of operation of ENVISAT, from 2002 and 2012, the mean night-time UHII over all land use classes ranged between $2^{\circ} \mathrm{C}$ and $3.5^{\circ} \mathrm{C}$, the highest night-time UHII values were associated the urban centres and high density residential settlement classes.

\section{CONCLUSIONS}

Comparison of the LST data with classified Landsat data revealed that areas with high levels of vegetation are cooler and thus have lower UHII values than less vegetated areas, while built-up areas and densely populated areas are hotter and have higher UHII values.

This study found that UHIs exist within the study area, at night the UHIE is strongest over Johannesburg's Northern Suburbs (as seen in Figure 4) and in areas where building density is high. The UHIE is weakest in areas that contain water bodies (such as dams 
and streams) or high levels of vegetation. Remotely sensed thermal infrared data is a valuable asset in studies of the urban environment, especially in areas where ground-based weather stations are spatially sparse. The AATSR dataset of Johannesburg is best used to study UHIs occurring at night since many day-time observations are not usable due to cloud cover, while the Landsat data for Johannesburg as only available for day-time scenes and thus the Landsat thermal data and Landsat derived land surface temperature can only be used to study the day-time heat island.

Classification maps (similar to that shown in Figure 3), derived from k-means classification applied over the optical and near infrared Landsat bands, can be used to supplement the AATSR night-time thermal data for a better understanding of the underlying urban environment and to determine the associated land use and land cover changes. Due to the combination of cloud cover, satellite overpass time and repeat cycle length, it is not possible to create a comprehensive time series of the complete study area. The use of satellite data from multiple sensors is required in order to study the dynamic nature of UHIs within the city.

Landsat data provides a high level of detail for spatial features, which is sufficient for the purposes of tracking and monitoring land use and land cover change associated with spatial variation in the UHIE. However, the largest shortcoming is data temporal resolution; the inclusion of thermal infrared and LST data from AVHRR and MODIS to the dataset may provide more cloud-free data to close the temporal gaps in the dataset, thus enabling better temporal analysis of the dataset and thus improving future UHII estimation.

\section{REFERENCES}

Adebayo, Y. R., 1987. Land-use approach to the spatial analysis of the urban 'heat island' in Ibadan, Nigeria. Weather 42(9), pp. 273-280.

Arnfield, A. J., 2003. Two decades of urban climate research: a review of turbulence, exchanges of energy and water, and the urban heat island. International Journal of Climatology 23(1), pp. 1-26.

Chen, J., Zhu, X., Vogelmann, J. E., Gao, F. and Jin, S., 2011. A simple and effective method for filling gaps in landsat ETM+ SLC-off images. Remote Sensing of Environment 115(4), pp. 1053-1064.

Goldreich, Y., 1985. The structure of the ground-level heat island in a central business district. Journal of Climate and Applied Meteorology 24(11), pp. 1237-1244.

Goslee, S., 2011. Analyzing remote sensing data in R: The landsat package. Journal of Statistical Software 43(4), pp. 1-25.

Maxwell, S. K., Schmidt, G. L. and Storey, J. C., 2007. A multiscale segmentation approach to filling gaps in landsat ETM+ SLC-off images. International Journal of Remote Sensing 28(23), pp. 5339-5356.

Peng, S., Piao, S., Ciais, P., Friedlingstein, P., Ottle, C., Bréon, F.-M., Nan, H., Zhou, L. and Myneni, R. B., 2012. Surface urban heat island across 419 global big cities. Environmental Science \& Technology 46(2), pp. 696-703.

Prata, F., 2002. Land Surface Temperature Measurement from Space: AATSR Algorithm Theoretical Basis Document. Kartographische Nachrichten 55(1), pp. 3-11.
R Core Team, 2015. R: A Language and Environment for Statistical Computing. R Foundation for Statistical Computing, Vienna, Austria.

Roth, M. and Chow, W. T., 2012. A historical review and assessment of urban heat island research in Singapore. Singapore Journal of Tropical Geography 33(3), pp. 381-397.

Statistics South Africa, 2012. Population Census 2011.

Taha, H., 1997. Urban climates and heat islands: albedo, evapotranspiration, and anthropogenic heat. Energy and Buildings 25(2), pp. 99-103.

Tyson, P., du Toit, W. and Fuggle, R., 1972. Temperature structure above cities: Review and preliminary findings from the Johannesburg Urban Heat Island Project. Atmospheric Environment 6(8), pp. 533-542.

Voogt, J. and Oke, T., 2003. Thermal remote sensing of urban climates. Remote Sensing of Environment 86(3), pp. 370-384.

Weiss, D. J., Atkinson, P. M., Bhatt, S., Mappin, B., Hay, S. I. and Gething, P. W., 2014. An effective approach for gap-filling continental scale remotely sensed time-series. ISPRS Journal of Photogrammetry and Remote Sensing 98, pp. 106-118. 